\title{
CARACTERIZAÇÃO DE PERFIS EXTRUDADOS DE LIGAS DE ALUMÍNIO SOLDADAS PELO PROCESSO DE ATRITO E MISTURA
}

\section{Matheus B. Martins*, Rodrigo J. Contieri.}

\section{Resumo}

A maioria dos produtos industrializados avançados é formada a partir da união de componentes individuais. Para aqueles cuja união deve ser permanente, um dos processos mais utilizados é a soldagem. Dentre os inúmeros tipos, destaca-se o processo de soldagem por atrito e mistura, também conhecido por FSW (Friction Stir Welding). A soldagem por fricção é um processo realizado no estado sólido (diferente dos processos convencionais em que existe a presença da fase líquida) que produz soldas pela rotação ou movimento relativo de duas peças sob forças compressivas, produzindo calor e deformando plasticamente o material na superfície de atrito. A partir desta técnica é possível obter juntas com menores distorções e maior resistência mecânica, proporcionando aplicações na indústria automobilística e aeroespacial.

\section{Palavras-chave:}

FSW, Atrito e Mistura, Alumínio.

\section{Introdução}

O objetivo do seguinte projeto é determinar as propriedades mecânicas de perfis extrudados de alumínio soldados por FSW em função dos parâmetros de soldagem impostos e da liga de interesse. Para isso, as juntas soldadas foram abordadas através da tríade: processo, microestrutura e propriedades, buscando minimizar efeitos adversos do processamento. A configuração estudada é de junta de topo de chapas de Alumínio da liga AA6005 na Têmpera T6.

\section{Resultados e Discussão}

A primeira parte do projeto consistiu na caracterização química, microestrutural e mecânica das amostras da liga AA6005 na Têmpera T6 extrudadas na espessura de $3,4 \mathrm{~mm}$ antes do processo de soldagem por atrito e mistura (FSW), reunindo as características encontradas no material com o previsto na literatura e, em seguida, buscando os parâmetros ideais de soldagem para a aplicação prevista.

Foi realizada a análise microestrutural e de fases através de microscopia ótica, seguida por microscopia eletrônica de varredura (MEV), difração de elétrons retroespalhados (EBSD) e difração de raios- $x$, obtendo resultados pouco discordantes do previsto para a liga, devido ao seu processamento. A fim de avaliar o comportamento mecânico e os mecanismos de fratura do material, as amostras foram submetidas à ensaios de tração e a fim de determinar a dureza do material, foram aplicados ensaios de microdureza Vickers.

$\mathrm{Na}$ segunda parte buscou-se encontrar os parâmetros ótimos de soldagem por FSW. Por meio de um equipamento dedicado à união por FSW, MTI GG-72.0 de 5 eixos, disponível no IPT-LEL (Núcleo de Estruturas Leves do Instituto de Pesquisa Tecnológica, São José dos Campos-SP). A ferramenta projetada e utilizada para soldagem dos perfis extrudados conta com ombro liso com $10 \mathrm{~mm}$ de diâmetro e pino liso de 2,80 $\mathrm{mm}$ de comprimento e $3,00 \mathrm{~mm}$ de diâmetro, e foi manufaturada em aço ferramenta $\mathrm{H} 13$.
Encontrando os parâmetros de soldagem, pôdese avaliar as diferenças de microestrutura entre as regiões do material como pode ser visto na Imagem 1. Imagem 1. Diferença microestrutural em cada zona.

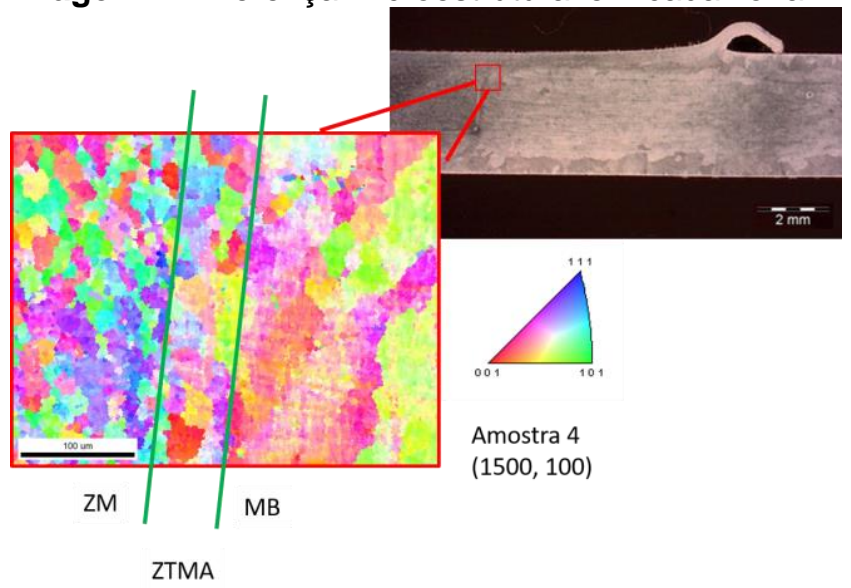

\section{Conclusões}

Os dados obtidos no projeto contribuíram significativamente na caracterização dos parâmetros de soldagem por FSW e seus efeitos na liga estudada. As avaliações preliminares apresentaram bons resultados e potencial para aplicação em curto a médio prazo.

A eficiência (ppm) chegou a mais de 60\% para algumas condições estudas, e ficou em $50 \%$ para grande maioria de parâmetros.

\section{Agradecimentos}

A caracterização das amostras o e estudo dos parâmetros de soldagem só foi possível graças ao convênio C2PA, onde a Votorantim Metais (CBA) forneceu as amostras e o IPT-LEL disponibilizou 0 equipamento de FSW.

\footnotetext{
1 C.C. Tutum, J.H. Hattel, Numerical optimisation of friction stir welding: review of future challenges, Sci. Technol. Weld. Join. 16 (4), 2011 318-324.

${ }^{2}$ G. Çam, M. Koçak, Progress in joining of advanced materials, Int. Mater. Rev. 43 (1), 1998, 1-44.
} 